\title{
Analysis on the Differentiation Management and Innovation of Czech and Chinese Luxury Brands
}

\author{
Zeng Sumei \\ Guangzhou College of Technology and Business
}

Keywords: Luxury brands; Differentiated management; Differentiated innovation

Abstract: Currently, with the rapid development of social economy, and the deepening of global economic integration, trade between countries gradually thrives. In fact, the trade contacts between eastern and western countries are gradually thorough. Besides, the development of economy gradually improves people's living level. People are more eager for a luxury brand and their consumption ability also gradually improve, but there are some differences in the luxury brand management form between different countries. Based on this, this paper will reveal luxury brand differentiation in management and innovation as the research object. Luxury brand, brand differentiation and differentiated management related concepts are expounded, and the bilateral luxury brand management present situation has carried on the brief analysis, based on the luxury brand management of the differentiation of native luxury brand management in China. This essay is to put forward the innovation strategy, to expect to provide certain innovation strategy for the development of China's luxury, at the same time, and provide references for Chinese luxury brand differentiation management.

\section{Introduction}

Chinese luxury consumption has, currently, more than $\$ 100$ billion in total, accounting for 52\% of the world's luxury goods consumption, although the luxury market share fell from country to country, but the luxury market in China is still on the rise year by year, more and more luxury goods companies attach importance to the Chinese market. In China market, the luxury brands gradually raise the proportion of occupied in the consumer market, especially the western luxury brand which occupied the market share gradually increasing with the brand strategy of gradual adjustment. The huge potential of China's consumer market makes the desire of luxury brands in various countries to enter the Chinese market stronger. For China and Czech, there are few local luxury brands, and they occupy fewer brand markets compared with other countries in the east and west, and their differences are also obvious.

\section{Related Concepts}

\subsection{Overview of luxury brands}

From an economic perspective, luxury refers to the product with the highest ratio between value 
and quality, while from a marketing perspective, the product with the highest ratio between intangible value and tangible value. Internationally, generally refers to the luxury goods are beyond the scope of human survival and development. With a relatively scarce, the unique consumer goods are also known as the necessaries of life, which can bring consumers and delicate way of life, paying more attention to taste and quality of products, products for the high-end market, and these products are divided into different brands, referred to as a luxury brand [1]. Luxury brands have specificity, f which brand is a product or service one kind of product, with the obvious personalization features. Moreover, luxury brand is compared commonly with other commodities has obvious difference in particular, which has strong features and personalized design, attention to detail, unlike public goods, the added value of the brand. In a sense of luxury brands, sales is not the product itself, but rather of the product contains can bring some kind of emotional sustenance for the consumer, luxury products, besides, it has the material with a strong emotional attributes, with its high value in one, in comparison with the other brands, including the top designers design, strict raw materials and exquisite handmade craft, not only the brand value is high, luxury brand products is of the best the embodiment. When carrying out market positioning, luxury brands usually provide services to the wealthy people in the high-end market, which makes people feel unattainable. This is to distinguish the customers in the high-end market from those in the middle and low-end markets, so that they can generate a clear sense of distance and superiority from the public.

\subsection{Brand differentiation and differentiation management}

Brand differentiation is an enterprise of its own products, to some special features and cultural orientation, individual differences of commercial decisions, is based on the total process of different brand image, that is to say, a particular brand is specified as a difference in the selling point of the brand and the market competition position, which is to be able to occupy a special place in the consumer and the market, giving full play to the advantages of the core of the product, in order to meet the personalized needs of target customers, by this way to transfer the brand information to consumers' hands, so it can lay the personalization in the consumers' mind status. And differentiated management is provided by the products and services with other competitor has obvious difference, thus forming a kind of different management strategies with other competitor, the core of this management is to obtain the uniqueness of thick have value for customers, its essence is to build a form of monopoly can, to be able to gain customer loyalty, in competition with other enterprise development of big contrast has obvious competitive advantage, differentiation management in the enterprise in competition need to provide the products to target customers and cannot be compared by the products offered by other companies, such ability can occupy the dominant position in the product competition. Customers are an important factor in differentiated management. Therefore, target customers are segmented from the vast market, and differentiated management strategies are formulated through personalized and ironclad customer evidence, so as to improve their competitive advantages.

\section{Comparative analysis of luxury brand management status between China and Czech}

\subsection{Market situation of luxury consumption}

\subsubsection{China's luxury consumption market}

For Chinese luxury consumer market, China's luxury consumer market size is very big, consumption mainly young upstart under the age of $40,75 \%$ of Chinese luxury consumers less than 45 years old, $50 \%$ of luxury consumers aged between 18 to 34 years old, highly educated, high 
income people is the main body of luxury consumption in China, which is given priority to with business success, entertainers and other groups, the current 80s, 90s students, after the official second generation, a representative of the rich second generation and luxury purchase, the consumer researchers with good economic foundation, has a blind pursuit for luxuries. China has the largest market for luxury goods in 2018 exceeded 140 billion yuan, sales personal consumer goods market in China in 2017 reached 142 billion yuan, more than 20\% year-on-year growth, total sales of 2 trillion yuan in global personal luxury market accounted for $8 \%$ of the sales, as shown in figure 1 , 2017 individuals from Chinese consumers in the consumer market contribution to the cost of more than 650 billion yuan, an increase of more than 12\%. For the luxury market, luxury goods consumption is generally has a consistency, the consumption of luxury goods group generally has a high quality of life pursuit, a successful person is more, the pursuit of a high level of spiritual enjoyment, and is generally have high income people, for the authentication of their values, and some of the people is the pursuit of fashion, pay attention to their own personalized fashion personality and self [2]. At the same time, in the case of Chinese luxury goods, mainly in jewelry, clothing, calligraphy and painting, and wine products, especially for jewelry and alcohol as a representative of luxury goods in China occupy a larger market share, including mao-tai in our country and other countries become people's recognition of China's luxury, has made a great contribution for China's GDP growth, the average annual growth rate reached $4 \%$, brand stores, flagship stores and electric business platform for consumer channels to make the purchasing and consumption of luxury goods more convenient, especially with the rise of online shopping, It provides a broad way of consumption for domestic and foreign consumers.

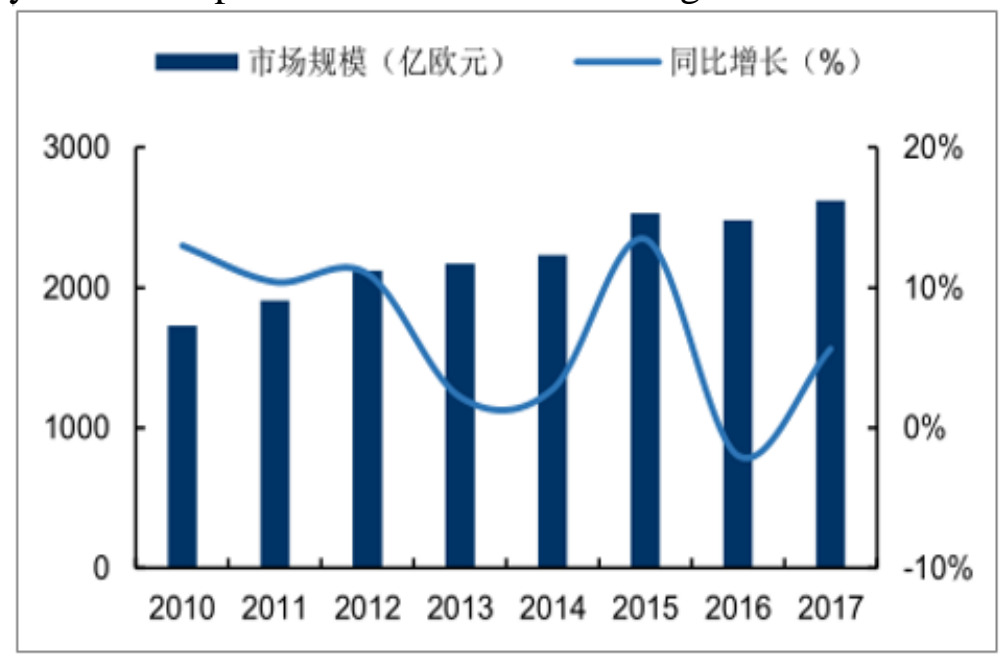

Figure 1 The size and year-on-year growth of the global personal luxury market in 2010-2017

\subsubsection{The Czech luxury consumption market situation for the Czech luxury consumer market.}

The Czech luxury consumption market scale is small, consumer groups are mainly concentrated in the middle class more than 40 more class, luxury consumption is more of a certain income, class is higher, the age of the consumer focus between 40 to 60 years old, which is given priority to with business, political and other groups, end luxury consumer group with good economic foundation. As for the luxury consumption market, the Czech market is rational to some extent. As one of the European Union countries, the wage difference in the Czech region is about 20\%, and the employees working in Prague pay more. Are mainly concentrated in the Czech republic luxury bags, jeweler, Musical Instruments, crystal and other industries, including bags brand Lerner is by numerous countries in the European royal, noble, and government officials, instrument brand SCHOLZE is a piano brand of luxury brands, and the Czech republic Preciosa crystal brand is one 
of the most famous crystal production in the world, and its production including crystal jewelry, crystal lamp, droplight, gifts and other related products exported to many countries in the world. Preciosa crystal would have the government diplomatic occasions, Its products are collected by politicians, companies and famous people in the world, such as Czech President VaclavKlaus. As an important luxury brand of Czech, it is used by well-known people and important places in the world. Although the Czech luxury brand is less, but its for the Czech national economic development still played an important role, the Czech luxury in the gross national product (GNP) share even though only $8 \%$, but its also formed a certain brand competitive advantage, but the Czech luxury sales channels generally is a physical store to buy, and custom, sales channel is unitary, the size of the market is small [3].

\subsubsection{Comparison of luxury consumption market in China and the Czech republic}

From the above analysis can play, China's luxury consumer market is mainly by 18 to 40 people with a certain economic basis is given priority to, consumer jewelry, clothing and other luxury goods, generally for women, alcohol, watches and other products consumers generally for men, consumption tend to be blind, too pursuit of fashion, performance, status, consumers towards younger and at the grass-roots level. China's luxury consumer market of consumer groups are mainly Chinese, the people of other countries less consumption, this is because the Chinese luxury with some foreign countries, especially western luxury than do not occupy the dominant position, consumer groups and consumer products which no effective development of China's luxury consumer market potential, but the product occupied market scale is larger, especially of online consumer channels, such as electric business platform development makes the product more consumption, the development of national economy also has a certain role in promoting.

For the Czech republic, its luxury consumption mainly concentrated in the middle class and high class of over 40 groups, economic strength, has certain rationality and consumption, consumption of products is also relatively fixed, affected by the Czech national luxury brands itself few its market scale is small, only account for $11 \%$, the market consumption group is fixed, the proportion of GDP in the national economy while only $8 \%$, at the same time, the Czech luxury sales channel is unitary, makes its products consumption quantity is less, for social and economic role is not obvious.

\subsection{Analysis of luxury brand management status of China and Czech}

\subsubsection{Differences in brand building and positioning}

Brand building and positioning is the act of building brand image and providing brand value, which is closely related to the cultural foundation. Any luxury brand needs to have its own brand building and positioning, so that its products can attract more consumers and bring different value experience to consumers. From the perspective of marketing, if high-end products can target customers for their own products, they can build consumer loyalty to the brand and transform luxury products into necessities. For Chinese luxury brand, our country to the construction of brand value degree is not enough, the more famous brands are numbered, such as mao-tai, seagulls, Kirin jewelry established product brand, the main form of mass consumption in our country is a line of luxury brands in other countries, such as Louis vuitton, CHANAL etc, these brands and brand in our country is in stark contrast, the luxury brand construction of our country, the development time is shorter, fewer sales time for luxuries, and the sales of luxury goods lies mainly in sales of luxury goods market, and with customers to establish a sales relationship, It has not formed its own cultural characteristics of luxury brands [4]. At present, our country product brand awareness and value in the product market and didn't get a good performance, although our country has some of 
the luxury brands, but the current our country brand awareness is still focused on the timing and the media, for other luxury brands such as yachts, car brand value, lack of good mining overall luxury brand of operational effectiveness.

For the Czech luxury brands, the Czech republic to the construction of brand value degree is higher, its influenced by other European countries for brand construction understanding early, especially on crystal brand construction is very early, as the world's most outstanding crystal base, the Czech republic's most representative Preciosa crystal brand has markets around the world, in many countries there are shops, formed the scale and the brand product sales form, this is based on the Czech for luxury branding and positioning of a form of sales. Czech republic , for the shape and positioning of the brand is relatively intact, is with more abundant brand culture connotation, clear brand positioning and rich cultural connotation that luxury brands get rapid development, business scale and market share is more significant, the overall luxury brand operation effect is better.

Anyway, for the jaguar luxury branding and positioning difference, shaping and positioning for luxury brands in China know, brand building, brand shaping ability is low, the lack of brand culture, for operation is also a lack of brand, compared with China, the Czech republic for product branding and positioning of understanding early, brand culture is rich, the construction is more focus on product brand, to compare the shaping ability is strong.

\subsubsection{Differences in brand mode management}

The correct brand structure is very important for product development and provides certain development space for product expansion. Advanced brand development thinking can promote product development. For Chinese luxury brands, China's huge consumer market for luxury brands to enter and development opportunities, but for local luxury brands in China, is China's domestic luxury brands the limitation of amount, size, type, etc, the current has only a dozen luxury brands, and this year to not line, the foreseeable future is the establishment of luxury brands in China and has over a period of time will not be changed, although the total amount of luxury consumption in China, the size of the market is rising, but mainly concentrated in Europe and the United States and other countries of the luxury brand in the consumer, Luxury brands in China overall operation is not the dominant, luxury brands in Guizhou mao-tai liquor as the representative, brand operation basically in the traditional culture as the main body, the major consumer groups for the Asian countries, Europe and the United States and other countries on the product's consumption ability is limited, branding market mainly in Asia, and for a luxury brands such as Kirin jewelry, sea gulls watches, brand operation, mainly in the domestic market by setting up brand shop to implement market development, overall less luxury brands in China, the brand also basically is given priority to with domestic market, by setting up brand stores and agents for operation.

As for the Czech luxury brand, the Czech market is relatively small, but as a member of the European Union, the overall European market is relatively large, which enables it to obtain the full agency and sales rights of luxury brands in several countries. For example, the agency sales of luxury brands like CHANAL, DIOR and Hunter are relatively low in price. Meanwhile, the operation of luxury brands of Larnur, SCHOLZE and Preciosa in the Czech republic is mainly based on the European market. By virtue of good brand advantages, the company has established sales agents in other European countries, combined the operation of domestic luxury brands with the luxury brands from abroad, and realized common publicity [5]. But, on the whole, bilateral less luxury brands, and brand operation is based on country and neighboring countries as the main body, just the luxury of the Czech brand more competitive in the world, and has distinct national cultural characteristics, such as SCHOLZE piano brand around the world have a competitive advantage, but China's luxury brands in the world within the scope of the rival is relatively weak, and the brand strategy is also imperfect. 


\subsubsection{Differences in brand operation}

The three elements of successful brand operation are brand technology, image and marketing. In terms of luxury brand management in China, first of all, as one of the most important jobs of a brand company, brand management, especially luxury brands, needs to have a higher proportion of value. With the expansion of business scope, the extensive promotion and marketing of various brands cannot meet the needs of current group brand promotion. Second, the brand enterprise brand is a lack of professional management, luxury brand management is mainly composed of marketing and sales department is complex, the lack of unified planning of brand management, the lack of specialized brand manager is responsible for brand promotion and the key point of contact, such as government, customers and business contacts is less, at the same time, the lack of professional talents cultivation of brand management and culture management [6]. China's luxury brands, such as mou-tai, are mainly responsible for the external publicity of the Marketing Department. Although they have a solid position as a luxury brand in China, they do not occupy a good market in foreign countries. Finally, there is a lack of corresponding supervision and evaluation in brand management. There is no clear operation and management system for the brand's domestic and international markets and regional markets.

In terms of the Czech luxury brand management, brand operation is essentially complete, although the French luxury brand is relatively small, but for the introduction of foreign luxury brands, and relative to the western European countries, the Czech republic luxury brand is low in price, product variety is complete, for the introduction of external luxury brand is more seriously, each brand promotion and marketing of work at the same time can conform with brand promotion needs. At the same time, the Czech republic's luxury brand enterprises usually have independent brand management departments, mainly by the Marketing Department is responsible for, the enterprise will be branded products for unified planning and positioning, brand strategy, the brand promotion also attaches great importance to the reputation, culture, and the application of the channel such as star, attach importance to developing all kinds of social public welfare activities, in addition, brand management in the construction and maintenance for marketing, public relations, special operations to achieve the effective supervision and evaluation, in general, the Czech luxury brand management more perfect, more professional compared to the Chinese luxury brand operation.

\subsubsection{Differences in brand promotion}

As far as Chinese luxury brands are concerned, their investment in luxury brand promotion has been gradually increased. In recent years, the number of brand tour events in various regions has been increasing, especially in Shanghai, Beijing, Hong Kong and other regions. The increase of promotional activities has significantly enhanced their comprehensive sales, and the brand effect has become increasingly obvious. In addition, major enterprises actively participate in brand recommendation meetings and exhibitions held by local governments or industrial associations, give full play to their overall marketing strategies in themed brand activities, jointly operate various peripheral products and brand featured products, and expand brand influence [7]. Luxury brands in China, however, the promoter for the connotation of the brand positioning of the property, value and interests, personality, the embodiment of the cultural elements such as inadequate, although these luxury brands in China have a certain cultural background, but they are still on the performance, both in terms of publicity before or on the package can be will the traditional culture of the brand, its combination with the modern culture and, at the same time lead to the problems in the promotion. For the Czech luxury brand promotion, SCHOLZE brand, for example, its on positioning is clear, the main is the history product brand, through the perfect brand promotion the 
top-level design of corporate branding strategy planning and management, the brand of reasonable use intermediate management unified management brand operation, different products promotion of reasonable utilization of resources, ensure the promotion will not overlap, the establishment of a complete framework for brand and brand management system makes the whole SCHOLZE branding and promotion play an important role.

\section{Innovation strategy of Chinese locall luxury brand management based on the differences between Chinese and Czech luxury brand management}

\section{1 brand building and positioning}

For local Chinese luxury brand quality and location, with the transformation of enterprise strategy, brand positioning and image is more important, the luxury brand as the theme, the customer value as the ultimate goal, based on customer demand as the guidance of the luxury brand service, from the traditional single luxury brand marketing to the diversified international top luxury resource platform and service transformation. Top Chinese way of life, the transformation of China's luxury enterprise strategy mainly focused on the following: First, in terms of the strategic management transformation of the enterprise, the enterprise needs to pay attention to market positioning, carry out market segmentation, and focus on the high-end market. In the high-end market, further segmentation should be made for limited edition, customized edition and regular edition, so as to improve the influence of the brand. Secondly, while expanding the enterprise, the company attaches importance to brand promotion, conducts in-depth analysis of the market, takes customer demand as the ultimate goal, and the product should conform to customer demand, so as to improve customer satisfaction with the product and brand. Third, use the strategic system to standardize the job responsibilities and work content of employees, centralize the market and expand the brand influence. Fourthly, while improving strategic management, luxury enterprises decompose their strategic objectives, systematically study the resource market of each small target, clarify market positioning and core competitive advantages, and implement strategic management according to opportunities [8]. In addition, the positioning of Chinese luxury brands should also build brand image based on cultural connotation, combine traditional culture with modern fashion elements or simply build distinctive brand features of traditional culture, expand consumer groups, cultivate customer loyalty, and promote the brand to go international.

\subsection{Brand model management innovation}

Model of brand management, the first Chinese luxury brands to build up the body of the brand, the enterprise will be to build China's most luxurious luxury brand core value, take advantage of the different products in its connection is established luxury products and services, and will give their brand licensing to other representative enterprises, enterprises in brand building and brand relationship and brand relationship between brand and customer interaction, enhance customer expression of brand positioning to brand attitude. Under normal circumstances, is the multi-brand strategy adopted by enterprises, such as the main brand + brands, such as compound brand management strategy, mostly Chinese luxury brand has a certain historical and cultural element and the characteristics of brand mergers, its product correlation is strong, for these products will need to highlight the characteristics of their products, will be for each product, for different consumer market, consumers will product classification, guarantee the audience for the advanced products, through the multi-brand strategy play independent characteristics of various brands, build the brand + sub-brand multi-brand operation strategy. 


\subsection{Brand operation innovation}

Brand operation innovation to establish and improve the brand operation management system and operation process reengineering, according to other luxury brand enterprise management system, and brand operation management organization consists of the management committee, Marketing Department, the department of brand and brand managers, brand commissioner, all levels of different functions have different permissions. For luxury brand management process: (1) establishing responsibilities clear strategic management organization to establish brand management committee, which is by the brand management of department, Marketing Department, production department and other departments, mainly responsible for the enterprise brand construction strategy, target and decisions, while dealing with sudden major public relations crisis event, such as brand and its only after get approval, President of plan to implement; After the President gets the strategic plan, he will send it to the deputy general manager of each market to implement the plan, and then distribute it to the brand department. After obtaining the strategic plan, the brand department conducts unified discussions, makes plans and arrangements for implementation after the review and completion, and formulates the specific procedures, measures and promotion strategies of brand management [9]. (2) the Marketing Department will strengthen cooperation with the brand department in product marketing to improve sales performance, expand brand influence, and promote products through exhibitions, experience and other ways; (3) the brand manager and the brand major are respectively responsible for the formulation, implementation and implementation of brand strategies, promotion and analysis of brand culture, implementation of industrial brand activities, and assisting the brand manager to adjust programs.

\subsection{Brand promotion and innovation}

First, strengthen the design of brand management organization, and establish the three-level brand management organization. The first-level brand management organization is composed of the brand management committee, which conducts unified planning and management of the brand, and introduces other brand management experts to form the first-level brand management organization. The second-level brand management organization is composed of the Marketing Department, which is mainly responsible for brand communication and promotion. The third-level brand management organization is divided into brand management department, which builds a new brand by attracting more talents like brand management, brand development, brand design and innovation. Secondly, the introduction of new media, expand marketing channels, we use WeChat public, weibo today's headlines and trill new media way to strengthen brand promotion, in the propaganda of traditional culture at the same time provide channels for brand promotion, using microphones, wild view WeChat public number of many fans groups such as promotion of luxury brand, through the form of content is king for fans to build new local Chinese luxury brand image, to expand its influence in the young group, attract more young group entered China established luxury brands, build new traditional brand influence [10].

\section{Conclusion}

This article through to the bilateral luxury brand differentiation strategy analysis of the two countries to get the current China and the Czech republic between the two countries of the luxury brands in branding and positioning, brand management, brand promotion and brand operation of this a few aspects to differentiation, the establishment of the two countries less number of luxury brands are widespread, the phenomenon of competitiveness is not strong, for these phenomena, obtained the Chinese luxury goods management can through the innovative brand positioning, 
brand management and brand operation, brand promotion strategy to innovate management, clear its luxury brand positioning, build luxury brands with Chinese characteristics and operation strategies, At the same time, by establishing a standard and reasonable brand management system to enhance brand equity value, expand the world influence of Chinese luxury brands, and achieve sustainable development.

\section{Acknowledgement}

Planning for the development of philosophy and Social Sciences in Guangzhou in 2017, 13th Five-Year. Topic name: Research on the cultivation path of local brand characteristics in Guangzhou under the new economic norm, subject number: 2017GZGJ16

\section{References}

[1] Chen jinliang. Analysis of differentiated luxury marketing strategies [J]. Business economics research, 2010,14 (25):33-34.

[2] shi xianlong. Brand innovation is the ultimate barrier to product differentiation [J]. Sales and marketing (management edition), 2012,22 (1):34-36.

[3] song ning. Innovative management differentiation [J]. National business (retail), 2012,18 (23):80-80.

[4] xu fanying. On brand differentiation and its innovative significance [J]. Shang, 2013,04 (15):82-82.

[5] wang luyao. Research on the status quo of brand marketing of small and medium-sized enterprises in China [J]. Research on modern state-owned enterprises, 2016,22 (14).

[6] liu xiaolian. Differentiated marketing strategy of enterprise brands in the context of globalization [J]. Intelligence, 2012,17 (3):14-15.

[7] ren guangjian. Discussion on brand differentiation strategy and corporate culture innovation of "kong fujia" [J]. Modern commercial and trade industry, 2008, 32(2):56-57.

[8] xuan shuhao. Research and implementation of differentiated brand system based on market segmentation [J]. China collective economy, 2014,18 (7):48-49.

[9] li ring. "the strongest brain" : "innovative content" is wang and "differentiated" brand strategy [J]. Modern communication (journal of communication university of China), 2014,36 (3):99-101.

[10] sun jing. Differentiation competitive strategy of clothing of local brands in guangdong [J]. Guangdong economy, 2014,21 (10):82-84. 